\title{
Techniques for Increasing Group Cohesion in the 5th Grade
}

Ștefănescu Andreia, Albulescu Ion, Iacob Lucica, Feldrihan Claudia 


\title{
Techniques for Increasing Group Cohesion in the 5th Grade
}

\author{
Ștefănescu Andreia ${ }^{a *}$, Albulescu Ion ${ }^{b}$, Iacob Lucica ${ }^{c}$, Feldrihan Claudia ${ }^{d}$ \\ ${ }^{a}$ Doctoral School "Educational, Reflection, Development", Babeș-Bolyai University, 7 Sindicatelor Street, Cluj-Napoca, 400029, Romania \\ ${ }^{b}$ Faculty of Psychology and Educational Sciences, Babeș-Bolyai University, 7 Sindicatelor Street, Cluj-Napoca, 400029, Romania \\ ${ }^{c}$ Ştefan cel Mare Secondary School, 36 A Gen. Grigore Bălan Street, 420016, Bistrița-Năsăud, Romania \\ ${ }^{d}$ Ştefan cel Mare Secondary School, 36A Gen. Grigore Bălan Street, 420016, Bistrița-Năsăud, Romania \\ *Corresponding author: stefanescu.andreia@gmail.com
}

Abstract

Keywords: group activities, cooperation, cohesion, cohesion techniques of the student group
The study sets out an exploratory research that aimed at testing some techniques for increasing the cohesion of the 5th grade student group. The techniques were included in the classes of counselling and personal development through group tasks in which the whole group of students was involved. The activity took place during the first school semester of the 2019-2020 school year. Following the application of the techniques, their viability was tested through a focus group discussion with 10 form teachers involved in the research. They described how the activity was carried out and the results obtained in the cohesion of the student class. The investigation is preliminary to that extended to the level of several schools, aiming to make the built techniques more efficient, in order to be widely applied, to the students in the secondary school cycle.

\section{Zusammenfasung}

Schlüsselworte: Gruppenaktivitäten, Zusammenarbeit, Zusammenhalt
Die Studie enthält eine explorative Untersuchung, die darauf abzielte, einige Techniken zur Verbesserung des Zusammenhalts der Schülergruppe der 5. Klasse zu testen. Die Techniken wurden in die Stunden der Beratung und persönlichen Entwicklung durch Gruppenaufgaben einbezogen, an denen die gesamte Gruppe von Studenten beteiligt war. Die Aktivität fand im ersten Schulsemester des Schuljahres 2019-2020 statt. Nach der Anwendung der Techniken wurde ihre Lebensfähigkeit durch eine Fokus Gruppendiskussion mit 10 an der Forschung beteiligten Führungskräften getestet. Sie beschrieben, wie die Aktivität durchgeführt wurde und welche Ergebnisse im Zusammenhalt der Schülerklasse erzielt wurden. Sie beschrieben, wie die Aktivität durchgeführt wurde und welche Ergebnisse im Zusammenhalt der Schülerklasse erzielt wurden. Die Untersuchung ist vorläufig für diejenige, die auf das Niveau mehrerer Schulen ausgedehnt wurde, um die gebauten Techniken effizienter zu machen, damit sie für Schüler im Sekundär Schulzyklus allgemein anwendbar sind.und -praxis in Einklang stehen.

\section{Introduction}

The educational systems and their policies in the contemporary period emphasize the importance of support for those who educate and for those who are educated, to understand that the science accepted by the present society is a professional approach whose preconceptions are related to the evolution of future generations. Thus, the dimension of education has to be re-shaped around an authentic educational society (Ionescu, 2007). Numerous studies reveal the existence of changes at the cultural level, predominating the preoccupations for the postmaterialistic axiological orientations the self-expression, the quality of spending free time, the socialization experiences that children and young people have and so on (Robu \& Ceranfil, 2018). In trying to include these elements in the educational context, we outlined a study whose overall objective is to increase group cohesion in the class of students. The choice of this theme is based on the fact that the high level of cohesion within the educational teams integrates all the elements with considerable impact on the learning process, namely, efficient relationships, socio-affective climate, group performance, group decision making and so on (Pânișoară, 2015)

In order to carry out this study, a series of techniques have been devised with the purpose to be used in the classroom. They were designed to change group dynamics in order to increase group cohesion. Their use during the lessons assigned to the subject "Counselling and personal development" aimed at accomplishing common tasks in which the whole group of students was involved. The techniques used allowed the students to become aware of the qualitative examination of the school contents and to respect the formal normative system in schools. The extent to which the requirements of the techniques were met were quoted with points that the students accumulated 
for a common budget. Depending on the total number of points accumulated by the entire group, a decision was made at group level regarding the reward they could receive from a service offer made available by the head teacher. It is important to emphasize that, as a result of the application of the materials, a pressure effect of the group has been installed on all the members where the common task has become a priority over the competition.

The article summarizes the main results of the activities carried out during the first semester of the 20192020 school year, and the centralization of the proposals for optimization of the elaborated materials, so that they can be extended at the level of several schools, to classes in secondary education.

\section{Particularities of cohesion in the class of students}

Formal education is one of the environments in which the individual can find recognition and social acceptance. On this subject, Weiss (2001) indicates that there are five types of social recognition: recognition as a member of a group; recognition in an assigned role; recognition in an acquired role; recognition in a public role (school performance ideally meets this requirement); the recognition of one's personal identity, of the uniqueness of each one. From the point of view of the principles that guide the theory and practice in the field of contemporary education, the emphasis falls on a series of values promoted by the postmodern paradigm, reflecting perspectives and solutions complementary to the classical and modern ones, adjusted to the needs of current societies in change, new directions, opening the need for educational projects adapted to them (Dahrendorf, 2010; David, 2017; Scott, 2006). The quality of learning, reflected in the European and internationally agreed quality indices, according to modern methodologies (Amundson, 2003; Moore, 2006; Scott, 2006), is often associated with a high quality of school group relationships, that is, motivated as a result of group interaction and thus achieve performance (Gilbert, 2010; Mullen \& Copper, 1994). This is possible in the presence of a high level of cohesion.

Cohesion describes the attraction force that a group exerts on the component members, through functions of control, influence, pressure towards uniformity and so on, and the result is the feeling of belonging and unity, respectively "we" (Dion, 2000). Pânişoara describes cohesion as "a phenomenon of the spirit of closure in the group", and for Festinger this is "the result of all the forces that act so that the members remain in the group" (Pânișoara, 2008, p. 230). As a psychosocial phenomenon, cohesion generates a series of psychosocial effects that are defining for the quality of life of a social group (Cristea, 2015). Cohesion is a fundamental characteristic of the syntax. This concept is introduced by Cattel to "distinguish and oppose the personality of the group from the personality of the individual", and in the school context "the class sense is a qualitative result, always something beyond and beyond the mere reunion of the distinct individualities" (Nicola, 1974, p.199). According to Krâsiko (2007), cohesion indicators are shown, on the one hand, by the level of sympathies expressed in the group, specifying that the higher the number of individuals who like each other, the higher the cohesion, and on the other hand, the extent to which there is a phenomenon of attraction of the group for its members, rendered in the number of people satisfied by their presence in the group, than of those who participate as a result has the advantages offered by the group. Cohesion was described in the 1950s as a "system of forces" acting on individuals to remain in the group (Festinger, 1947, beside Ilut, 2009), the concept being seen, from the 1960s, as an interpersonal attraction ("force") within groups (Lott \& Lott, 1965, Cote Dion, 2000). The multifunctional models of cohesion were present in the literature of the 1980s and 1990s in social psychology and psychology, being famous for Carron's hierarchical model (1988, beside Dion, 2000), and after the 2000s the focus falls on how cohesion dimensions can be quantified for application in research and intervention. Thus, twodimensional models of analysis (task and social cohesion, vertical and horizontal cohesion, belonging and morality, personal attraction versus social attraction) are built. The importance of studying this social phenomenon in the context of the school groups lies in the fact that, on the level of cohesion, the way in which the dynamic activity in the school is carried out (Sălăvăstru, 2004). Research in the field (Beal, Cohen, Burke, McLendon \& Christy, 2003; Mullen \& Copper, 1994) has shown strong correlations between cohesion and performance. The performance obtained by the group is a synthetic indicator of the evaluation of the extent to which the basic social functions are fulfilled (Neculau, 2007). In this sense, it can target the social, professional, educational plan, etc. (Cristea, 2015). In all aspects of cohesion, it can be added that emotional experiences and especially emotional closeness play a mediating role in the feeling of belonging 
to the group. Also, motivation is an essential vector in obtaining the performance and legitimizing the value of the individual in relation to the others (Weiss, 2001), previously mediated by the feeling of group cohesion (Dion, 2000; Rouchy, 2000). A research on the opinion profiles on the mechanisms by which the interpersonal relationships are built (and the social capital is developed - at its bases there is the feeling of belonging ), carried out in 12 European states (England, Belgium, Denmark, Finland, France, Germany, Ireland, Italy, Poland, Portugal, Spain and Sweden), which interviewed 1490 adults of both sexes from different social categories over 18 years, indicated that the education system - formal and informal - is considered the most important environment for friendship (cohesion) but also for result and performance orientation (Van Oorschot, Arts \& Gelissen, 2006). In addition, research is consensual about the fact that when group members feel satisfaction (motivations of several types), mental comfort and a feeling of security, cohesion increases (Rouchy, 2000).

Based on the results of the theories and studies synthesized above, the program proposed by the present research aims to verify the degree of certainness with which the educational programs carried out in the classroom can increase cohesion and thus optimize adherence to the school environment and school performance.

\section{Research methodology}

\subsection{The purpose of the research}

The purpose of the research is materialized in the testing of the efficiency of some educational intervention techniques in order to increase the group cohesion in the 5 th grade.

\subsection{The research objectives}

The objectives of the research consist of the following:

O1. Design of educational intervention techniques that stimulate the change of group dynamics in the class of students in order to increase the group cohesion.

O2. Outline an educational program to increase the cohesion of the group on the techniques of educational intervention.
O3. Continuous training of leading teachers in order to apply the techniques of increasing cohesion in the classroom.

O4. Applying the techniques to the 5th grade learners during the first semester of the 2019-2020 school year, at the subject "Counselling and personal development".

O5. Evaluation of the efficiency of the proposed techniques through a focus group among teachers

\subsection{The research hypothesis}

The educational program applied to the 5th grade learners at the subject "Counselling and personal development" will lead to the modification of the group dynamics in order to increase the group cohesion.

\subsection{Research methods and tools}

In order to test the efficiency of the techniques of increasing cohesion, the focus group method was used, through an interview guide.

The interview guide applied to the completion of the activities carried out during the semester was structured on the following topics of discussion:

a) How did the proposed activity (map in Romanian language class, menu for observing the rules, accumulation of points, followed by the purchase from the mall) go to your class? In what way have you succeeded in introducing these tasks into the flow of educational activities to the class you are in charge of?

b) How do you generally evaluate these types of activities? Are they interesting, do they make a real contribution to students in interpersonal relationships and communication, group cohesion? Explain in which areas they are beneficial or quasiuseless and why.

c) Were the students sufficiently motivated to complete the tasks? If yes or no, why do you think this has happened?

d) The way the students used the materials was creative, they got involved, they looked for solutions, or they just tried to carry out for the task without motivation? Please describe how they manifested themselves (for both situations).

e) Thinking about the relationship between cooperation and group cohesion, what can you tell us 
about how the students manifested themselves during their activities? To what extent did one dimension or another prevail? Why do you think this has happened? Describe possible causes, influencing factors.

f) Regarding the aspects of communication and networking in this activity, mention some problems (weaknesses) that you have encountered, respectively some benefits (strengths).

g) If this is the case, what would you improve on the activity / this type of activity?

The tools used in the research targeted the techniques that include the school content for the subject "Romanian language and literature", one material that targets the normative system and another that constitutes the reward system for the class group.

The first technique built was to create a special map for Romanian language classes, which includes a route similar to an itinerary sprinkled with fun tasks and rewards in case of success.

Regarding the assimilation of effective rules of relation by the students, a funny "menu" was created in such a way as to stimulate the cooperation within the classroom. Actions are grouped into categories of rules to be followed and each reward is offered a reward, respectively for each violation, a penalty. Rewards and punishments are at points converted into money (euros), obviously fictitious, but with psychological value and potentially stimulating for the whole class to feel that they have accumulated "power" and have the capacity to enhance the group's successes and to legitimize the competence of the whole class (the feeling of cohesion). Penalties are also converted into money losses.

Following the accumulation of points by the whole group, the reward consists of purchases from the school mall, the options for the desired things being evaluated through the collective analysis of needs and priorities, and after the negotiations of the moderate class of leadership (argumentation of different points of view, discussions free items) will be purchased from the important items considered important for the whole group, depending on the amount accumulated through the effort of each student.

\subsection{The group of subjects}

The sample of exploratory qualitative research consisted of: the group of the form teachers - 10 subjects from Bistriţa-Năsăud county, from the rural and urban areas. They were offered working materials consisting of the techniques built with the mentioned purpose, as well as the activity chart. With the leaders there was a preliminary training for their activity with the students, to apply the techniques to the classroom and to standardize the evolution of the activities, as well as the results obtained during the 1st semester. At the end of the period, a focus group was organized with the teachers involved to gather relevant information on the efficiency of the class cohesion program.

\subsection{Research procedure}

In the exploratory phase of the research, the aim was to regulate the mechanisms by which the school motivation is stimulated by cooperation in order to obtain the group performance. The continuous training of the teachers in the research project integrated in this study aims to prepare the teachers who are at the same time form teachers for the development of the educational program in the class of students. The practical objective of this approach is to identify flexible psycho-educational intervention techniques in line with the optimization of the relationship between cohesion and performance, which take into account the characteristics of the group of students and at the same time facilitate the continuous training of teachers. The first stage of the exploratory research targeted the executives in order to develop their competence to use the techniques intended for efficient relationships, focusing on increasing the cohesion of the group (in the classroom), through a program of playful techniques, based on the relational dynamics between the students. In the second phase of the exploratory phase, at the level of the students, the main objective was the evaluation of school motivation in a group context, correlating the feeling of responsibility (belonging) with that of reward (motivation), through some mediating purpose-factors: performance and cooperation. The executives had to apply to their technical classes and to write down weekly the results, the changes observed at the class level and the problems encountered.

\section{Presentation of the focus group with the teachers.}

As a qualitative research endeavour, the focus group with leaders is useful in the pre-testing phase of the built 
techniques, in view of possible modifications of the strategy or of content elements of the working tools to be applied at a wider level, in schools. The focus group method is devoted to social sciences, the tool being very useful for collecting data from participants in order to rectify, complete and carefully analyze the methodological variables and factors from the exploratory phase that will be considered in the subsequent research (Chelcea, 2008), as well as at the end of some investigations, in order to collect qualitative data and thus enrich the conclusions (Rotariu \& Ilut, 2006). In this research the focus group method for exploratory research was used, prior to the actual one. Therefore, we have now limited ourselves to recording the way in which the application of these techniques (mode of development, interest and motivation of the students) is received and the problems at the level of the effective tools, so that the research strategy can be improved before administering the techniques to extended scale.

The experiences described and the suggestions from the participants to the focused discussion came as a specialized complement to the strategy and methods initially conceived, in the idea of perfecting both the techniques and certain constituent elements of the proposed activities but also of identifying the registered vulnerabilities of the activity of increasing the cohesion of the class.

\subsection{Creating the focus group}

Several participants were invited: Participant 1 (P1) $\mathrm{F}$, teacher of Romanian language, rural school; Participant 2 (P2) - M, teacher of Romanian language, urban school; Participant 3 (P3) - F, teacher of religion, school rural; Participant 4 (P4) - M, teacher of geography and history, rural school; Participant 5 (P5) - F, democrat teacher, rural school; Participant 6 (P6) - F, Romanian teacher, urban school ; Participant 7 (P7) - F, mathematics teacher, urban school; F, Romanian teacher, urban school; Participant 8 (P8) - F, Romanian teacher, urban school; Participant 9 (P9) - F, teacher of Romanian language, urban school; Participant 10 (P10) - F, teacher of education / social sciences, school urban environment.

Audio recording: with miniport and written observation notes.

Duration of the focus group: $1.45 \mathrm{~h}$
Period and place of the performance: 19.02.2020 (starting at 14.30), within a lower secondary school in the town of Bistrița, Bistrița-Năsăud county.

Rules of conduct: Presentation of the organizer and the moderator;

Presentation of the focus of the group and the topic of discussion: the participation of the leaders in the exploratory research project that aims to identify the most suitable techniques for increasing cohesion in the classroom, with the mention of the importance given to the honesty of the answers, in this way being able to improve and adapt the methods and strategies developed until now, in the exploratory stage, to the real needs of the students in order to increase the performance and the interest for the school through the feeling of cohesion. Ensure that the personal data of the participants are confidential and the results will be used only for the aforementioned purpose, in accordance with the ethical principles agreed in the scientific community.

Then, the participants' self-presentation took place in the focus group (institutional affiliation, taught disciplines / function). The questions were addressed to each one, one at a time, in order of the presentation. The participants had 2-3 minutes to answer each question. The duration of the entire discussion was 1 hour and 40 minutes. At the end of the discussions, the most relevant conclusions on each topic addressed were drawn. The ten participants intervened, circularly, on almost all the proposed themes. Where they had nothing to add to what the previous speakers had said, this was noted. The conclusions for each topic addressed were unanimously outlined, mentioning the reservations or completions of some of the participants. I mentioned in brackets the code of each member of the focus group (P1 - P10) where their interventions are cited or synthetically reformulated.

\section{Results}

In the rows below we present the main ideas that emerged after the group meeting, with the synthesis of the intervention of the participants. The full focus group responses are included in the detailed research report. As some questions were inevitably raised as intersecting topics, being discussed by the group members at another point during the discussion, we will outline below sections with the central topics that have been addressed. The references and the extension to the other topics, within them, made the subsequent resumption unnecessary (by 
addressing the question), these topics being dealt with at the appropriate moment in the course of the discussion.

The focus group topics are described below:

Table 1. The way of carrying out the tasks, their integration in the flow of activities
$\mathbf{P}$
Summary of the intervention
Relevant transcripts

1 It points to the difficult management

We encounter many problems with time management, because of time allocated to extracurricular there are many activities to be done outside the hours and the activities and the initial reluctance of students to other tasks assigned to the class. students see almost any proposal as an extra task and not as a useful fun. Because students often have problems concentrating, it took about a week until they understood exactly what to do and up to date the whole class.

2 It does not indicate problems of introducing the activity within the other school and extracurricular tasks.

3 It shows that from the point of view of time management there are many problems, because it has an extremely competitive class, oriented to individual success (stimulated by parents) and few of the performers want to participate in anything other than formal hours.

$4 \quad$ He states that the tasks have been completed without problems, and the activities have integrated harmoniously into the flow of the others provided in the curricula and in the extracurricular ones.

5 It does not mention problems with the way it is organized or organized.

6 It is noted that the problem of the flow of tasks / the repeated training addressed to the students and the problem of monitoring (the task of the class leader or other designated student, the observation sheets being centralized by the principals) are important.

7 No problems in the organization are reported.
The children reacted with interest and we succeeded in managing all the steps to make the required recordings. Time is limited, although students have found time to participate and advance with the accumulation of points. The workload is high at all times, so it was not possible to keep track of how these techniques worked.

The students were very interested in the menu for compliance with the rules and asked many questions that helped me organize the program during the classes. Through the positive stimulation of the participants the flow of activities went by itself. They dealt with themselves practically.

The proposed activity was very interesting to my 5th grade students, as they are curious about everything that is new, they have become more responsible, they helped each other a lot among themselves. There were no organizational problems.

The map for the Romanian language and literature discipline and the menu for observing the rules were extremely useful. The flow of tasks was more difficult to introduce because I had to give further explanations. The most troublesome was the monitoring part.

The map for the Romanian language and literature discipline and the menu for observing the rules were extremely useful. I had no problems with the management of the activities, it was fun and exciting. 
8 It indicates the effort put into management but appreciates the benefits of the program at the motivational level and in the results (notices the enthusiastic atmosphere in the classroom).
I teach Romanian language in four $\mathrm{V}$ grades (including the class I am the form teacher to), and with the map I had a lot of work, but it was worth it because they were more aware of what they are learning, they had a visual support that reflects their instructive course and so were motivated. Once a week we tell them how many euros the class has accumulated. The children were always very excited.

9 No problems in the organization are reported.

The activity proceeded normally, the students attended carefully, they showed seriousness and interest.

10 No problems in the organization are reported.

I managed to apply the map to the classroom by using Romanian language in collaboration with the teacher and the students managed to raise Euro for the homework, paying attention to the time and the learning. At the time of the management the students accumulated Euros for cleaning, discipline in class and breaks.

Table 2. Evaluation of activities in several aspects

\section{P Summary of the intervention Relevant transcripts}

1 It shows how the students engaged in cooperation, how they managed to organize themselves but also how they helped each other, the importance of group leaders who acted cohesively.

\section{It describes the enthusiastic way in} which the students received the map in Romanian language, the amusement aroused by the menu of norms was launched from the beginning, but keeping the spirit of fair play in relation to colleagues who did not accumulate enough points (money).

3 It describes how the class is segregated into very good students and very weak students, which created from the beginning a barrier to class cohesion as a whole.
The activities are useful and helpful. The students who had the highest degree of initiative were involved from the beginning, so I saw that they were able to come together if they had a common purpose and were motivated. The money motivated him and behaved as if it were real. It's an age when I get these kinds of activities. The shyest ones did not manage to maintain the step from the beginning, but were pressured by the others to keep up with them.

In my opinion, children should be involved more often in such activities because it creates a good atmosphere for cooperation, a balance. They like the money and have enjoyed the sum collected as something real. They just waited, at the end of each week, to see what they could buy.

Some have given up their interest because of the very good learning leaders who have made great progress in the beginning and thus they have lowered the confidence of the weakest.

\footnotetext{
4 It stresses the usefulness of They are useful in broadening the horizon of knowledge and selftechniques in personal development knowledge. I think the most useful ones are in the curricular area and on the dimension of social of "Man and society" integration.
} 


5 It indicates the interest of the The proposed activity was very interesting to my 5th grade
students precisely because of the students, as they are curious about everything that is new, they
playful aspect and the fact that being have become more responsible, they helped each other a lot. Such
an extracurricular activity it attracts activities are welcomed, as they somehow bring students out of
children. Emphasizes mutual the area of strictness, rigidity.
assistance in carrying out tasks.

6 It mentions the benefits of The activities are interesting, stimulate creativity, ambition and developing individual skills. the courage to take on an answer or solve an exercise.

7 Such activities are considered Through motivation and responsibility, the students were hired interesting and useful. until the end in the program, in fact he continued now, after theoretically it was over ... the techniques are challenging and I have really noticed a change.

8 It emphasizes the importance of The tools you have provided me with have been a means by which establishing a common goal and students really feel rewarded for their effort to learn and behave describes the positive dynamics and responsibly. Being the form teacher of a 5 th class that, in the first interest expressed by the student for weeks, raised a number of small but disturbing problems, I used this program. the idea presented and I managed to motivate them positively because they had an immediate purpose that they could achieve only with all having inappropriate behaviour. I also gave fines, but I bought from the school mall a Halloween party, a week in which they stayed in the banks with whom they wanted, a week without a uniform, an hour of running with interesting games, postponing a test. And all with great enthusiasm from the children.

9 It insists on the benefits on the I find these types of activities interesting, being appreciated by cohesion dimension and the students. They develop both their communication skills and their motivation of the students through relationship with others. During the counselling hours, these the exciting nature of the proposed activities were beneficial because it helped them to be more techniques. united, following the rules of the class, so as to accumulate as many points.

10 It indicates the attractive means The students were delighted with the idea of earning euro and (rewards) through which the spending it further. They connected and communicated communication and networking was wonderfully with each other for the purpose.

achieved within the class.

Table 3. Synthesis of the interventions to improve the program: Strengths / Weaknesses - Proposals to improve the techniques

\section{\begin{tabular}{lll}
\hline & Summary of the intervention $\quad$ Relevant transcripts
\end{tabular}}

1 Strengths: spontaneous participation. The strong point is that the students actually participate in this activity, without stimulating it further. The weak point is the lack 
Weaknesses: insufficient time.

Sanctions should be established and felt as a group loss. of time for activities outside the curriculum.

It would be good to think that the non-observance of the group norms should be amended more seriously, so we educate them to be more aware of those around them, of the needs of others.

The strengths would be that the students can evaluate themselves, translating for them the points obtained and can be corrected without receiving directions from outside.

information.

Weaknesses: organization and control.

The suggestion of making maps for other disciplines, and the techniques to be developed in such a way as to cover several levels of difficulty.

The weaknesses are the organizational ones and the control of the situation.

Maps to other disciplines would be welcome. There are students who come with big gaps in the primary classes and even functional illiteracy. It is difficult to explain to them a more complex game that they can play just like the others. I think it would be good to develop techniques with different levels of difficulty, if you reach a level to move on to the next and so on ... to work differently with children, as we do at hours, depending on the capacity of each.

$3 \quad$ Strengths: interesting and participatory game

Weaknesses:Propose additional game themes to enhance class cohesion.

$4 \quad$ Strengths: team cooperation

Weaknesses:large number of students.

It was a lot of fun from the start and a few weeks ago this was the topic in all the breaks. The game should include fines in case of fraud (....) in case of sabotage of colleagues, for example. Let's not encourage fierce competition.

As a strong point I would mention the cultivation of the team spirit. The weak point I would say is the large number of students in the classroom that affects any activity, it is not possible to work effectively in classes with over 30 children.

It has no improvement proposals.

$5 \quad$ Strengths: beautiful materials, responsibility, cohesion created through activities.

Weaknesses: -Making maps on several subjects.
The strong points are the beautiful materials, the responsibility of the students, the unity between the colleagues, I saw how they collaborate, how well they relate to reach their goal. Such a map would also be useful in mathematics.
$6 \quad$ Strengths: group stimulation, attractive activities

Weaknesses: the resource of time

$7 \quad$ Strengths: the game aspect of the activities
The strong points are the stimulation of all the students and the attractive activities

Weak points are not too much, but we are facing a lack of time.

The strong point is that everything becomes a play and is not felt as a task for students. The weak point is that they fail to collaborate effectively, the whole class (...) small groups that 
Weaknesses: low class cohesion

compete with other groups.

$8 \quad$ Strengths: positive effects on

cohesion, networking and

communication, team feeling.

Weaknesses: time resource, activity management and monitoring.

Enriching the list of products to stimulate motivation.
The strong point is certainly that these tools increase the cohesion of the group because it involves the whole class, and the fine received by a student influences the budget of the whole class. The students practiced negotiation, communicated effectively and collaborated, feeling that they were a team.

The weak point is the lack of time and the management of the monitoring by the Romanian teacher or teacher.

It would be ideal to have material and time resources that allow us to offer students in "mall" more attractive products to increase their motivation.

9 Strengths: stimulating materials, useful and enjoyable way of assimilating through the game.

Weaknesses: Loss of self-esteem in those who have not accumulated points.
The strengths were at the level of stimulation, the students creatively used the materials involved in the given tasks. Applying the map to the Romanian language, learning was no longer a pain for the students, but it was a real pleasure. The students were aware that all information can become interesting, which will be useful later. As a problem, in the activities we encountered problems such as the loss of self-esteem if the students did not reach their goal or lost the first place.
10 Strengths: effective communication and networking, easy way to insert tasks through the game

Weaknesses: lack of covering other disciplines. Suggestion:

Development of the program to adjust to several disciplines.
The strong points were the good communication, the effective relations, the easier way of accomplishment of the activities through the game.

I propose to develop the applicability of the techniques in several disciplines.

\section{Conclusions}

The main findings from this study are detailed in the following: the proposed techniques prove to be useful and attractive to students. The motivation for involvement in the game is high. The students feel an optimal balance between rewards and punishments, in order to assume responsibility but also to positively legitimize the good behaviours and results. At group level, tasks involve cooperation and succeed in creating the feeling of cohesion. However, there have been situations in which problems of class segregation arisen, mainly due to the large differences in academic skills. The factors of increasing the cohesion that are shaped by the research are: the common purpose, the functional competition, the 
feeling of control by self-evaluation, the rewards and legitimation of the effort, respectively the sanctions for violating the norms. Depending on the environment in which the students come from, certain specificities emerge. In this regard, it has been proposed to develop different techniques, by degrees of difficulty, to cover the category of students who fail to participate in complex games from the beginning. Due to the success of the map from the Romanian language, several leaders have proposed the creation of such materials and other school

\section{Authors note:}

Andreia Ștefănescu is a Doctoral Student at BabeșBolyai University Cluj-Napoca. She is currently studying the phenomenon of cohesion within schools groups currently the. Mrs. Ştefănescu is also President of the Romanian Association for Research and Innovation which provides professional training courses for teachers accredited by the Ministry of Education and Research. Mrs. Stefanescu Andreia.

Albulescu Ion is habilitated Professor and Ph.D. Coordinator at the Faculty of Psychology and Sciences of Education (Babeş-Bolyai University, ClujNapoca, Romania) Department of Educational Sciences, Faculty of

\section{References}

Amundson, N. (2003). Active engagement: Enhancing the career counselling process (second edition). Richmond, B.C., Canada: Ergon Communications.

Beal, D.J., Cohen, R.R., Burke, M.J., McLendon, C.L., \& Christy, L. (2003). Cohesionand Performance in Groups: A Meta-Analytic Clarification of Construct Relationships. Journal of Applied Psychology, Vol 88 (6), Dec 2003: 9891004. doi: 10.1037 / 0021-9010.88.6.989.

Chelcea, S. (2008). Research methodology in the social sciences. Bucharest: Economic Publishing House. .

Cristea, D. (2015). Treaty of social psychology. Bucharest: TREI Publishing House.

Dahrendorf, R. (2000). Universities after communism. Hamburg: Edition Körber-Stiftung.

David, O. (2017). Career from the perspective of positive psychology. In A. Szentagotai \& D. David (Eds.), Treatise on positive psychology (pp. 283-300). Iasi: Polirom Publishing House.

Dion, K.L. (2000). Group cohesion: From "field of forces" to multidimensional construct. Group Dynamics: Theory, Research, and Practice, Vol 4 (1): 7-26. doi: 10.1037 / 10892699.4.1.7. subjects. The exploratory research described above has highlighted the importance of flexibility and contextualization, which is in agreement with the trends mentioned in the literature. This implies a joint effort by the researchers: to prepare the techniques, to carry out adapted trainings with the teachers and to follow the results at the level of the cohesion indicator of the class of students, followed by specific indicators of school performance.

Psychology and Educational Sciences. His research interest is reflected in a series of studies, articles and books published by prestigious international and national editors. Professor Albulescu teaching and research area covers several educational domains such as Educational Alternatives, Comparative Education, Pedagogical Theories and History of Educational Thinking etc.

Iacob Lucica is the Headteacher of Stefan cel Mare Secondary School in Bistrita-Nasaud, Bistrita County.

Feldrihan Claudia is the Deputy Headteacher of Stefan cel Mare Secondary School in Bistrita-Nasaud, Bistrita County

McGaw (Eds.), International Encyclopedia of Education (third edition) (pp. 510-513). New York: Elsevier Ltd.

Iluț, P. (2009). Social psychology and sociopsychology. Recurring themes and new visions. Iasi: Polirom Publishing House.

Ionescu, M. (coord.) (2007). Conceptual and praxiological approaches in the education sciences. Cluj-Napoca: Eikon Publishing House.

Moore, A. (Ed.). (2006). Schooling, Society and Curriculum. London, New York: Routledge, Taylor \& Francis Group.

Mullen, B. \& Copper, C. (1994). The relationship between group cohesiveness and performance: An integration. Psychological Bulletin, Vol 115 (2): 210-227. doi: 10.1037 / 0033-2909.115.2.210.

Neculau, A. (2007). Group and team dynamics. Iasi: Polirom Publishing House.

Nicola, I. (1974). Microsociology of the student body. Bucharest: Didactic and Pedagogical Publishing House.

Pânișoară, I.-O. (2008). Effective communication. Iasi: Polirom Publishing House.

Pânişoară, I.-O. (2015). Effective communication (fourth edition). Iasi: Polirom Publishing House. 
Rotariu, T. \& Iluţ, P. (2006). Sociological survey and opinion poll (second edition, revised). Iasi: Polirom Publishing House. Rouchy, J.K. (2000). Group - Analytical space. Iasi: Polirom Publishing House.

Sălăvăstru, D. (2004). The psychology of education. Iasi: Polirom Publishing House.

Scott, D. (2006). Six curriculum discourses. Contestation and edification. In A. Moore (Ed.), Schooling, Society and
Curriculum (pp. 31-42). London, New York: Routledge, Taylor \& Francis Group.

Van Oorschot, W., Arts, W., \& Gelissen, J. (2006). Social capital in Europe. Measurement and social regional distribution of a multifaced phenomenon, Acta Sociologica, 49 (2): 149-167.

Weiss, O. (2001). Identity Reinforcement in Education: Revisiting the Symbolic Interactionist Legacy, International Review of the Sociology of Education, 36: 393-4. 